\title{
PENENTUAN NILAI KONTRAK OPSI SAHAM TIPE EROPA MENGGUNAKAN MODEL CONSTANT ELASTICITY OF VARIANCE
}

\author{
Lusia Emitriana Magol $^{1 \S}$, Komang Dharmawan ${ }^{2}$, Desak Putu Eka Nilakusmawati ${ }^{3}$ \\ ${ }^{1}$ Program Studi Matematika, Fakultas MIPA - Universitas Udayana [Email: lusiaetri13@gmail.com] \\ ${ }^{2}$ Program Studi Matematika, Fakultas MIPA - Universitas Udayana [Email: k.dharmawan@unud.ac.id] \\ ${ }^{3}$ Program Studi Matematika, Fakultas MIPA - Universitas Udayana [Email: nilakusmawati@unud.ac.id] \\ ${ }^{\S}$ Corresponding Author
}

\begin{abstract}
Investment is a very sensitive matter especially relating to securities commonly known as shares. Shares are not merely as securities or certificates of ownership but as a business area in achieving profits. One alternative factor for investment is option. Stock options are one of the trading tools used to secure stock investments owned by investors. The real value of stock options can be known when the due date. The stock option value formula can be used to find out the value before the due date. The most widely known stock option value is to use the Black-Scholes equation which is obtained from a constant volatility value. Then it was developed because it saw the conditions in the market based on the volatility of the value (not constant). The purpose of this study is to determine the value of stock options in the market based on volatile values that change using the Constant Elasticity of Variance model with the limit of European stock purchase options. If the resulting stock option value is greater than the option price in the market, investors are advised to buy the stock option.
\end{abstract}

Keywords: Stock Option, Model Constan Elasticity of Variance

\section{PENDAHULUAN}

Dewasa ini pasar modal sudah sangat berkembang sebagai tempat jual beli beberapa asset keuangan yaitu saham. Dengan adanya pasar modal dapat menjadikan sarana untuk peminjaman uang bagi yang membutuhkan tentunya tetap mengikuti persyaratan dan aturan yang telah ditetapkan. Perkembangan pasar modal dunia mengalami beberapa kali kondisi pasang surut, begitu juga di Indonesia. Hal ini menyebabkan investor merasa kurang tertarik untuk menginvestasikan kekayaannya di pasar modal, sehingga dari permasalahan ini muncul turunan instrumen keuangan yang menarik kembali investor untuk berinvestasi. Turunan instrumen keuangan yang digemari para investor adalah opsi saham. Transaksi opsi saham mampu meminimalkan risiko kerugian yang mungkin dialami oleh investor saat berinvestasi, akan tetapi bukan berarti melakukan transaksi opsi merupakan hal yang mudah. Dalam melakukan transaksi opsi banyak hal wajib dipertimbangkan seperti kapan saat membeli dan kapan pada saat menjual, bagaimana perkembangannya, tingkat harganya, mempertimbangkan risikonya, serta strategi yang digunakan dalam memperoleh keuntungan dari transaksi opsi tersebut.

Pada tahun 1973 Black \& Scholes menemukan perhitungan harga opsi saham yang sering dipakai yaitu model Black-Scholes. Model Black-Scholes hanya dapat digunakan untuk menghitung opsi saham jual maupun opsi saham beli tipe Eropa serta terdapat nilai volatilitas yang konstan. Volatilitas merupakan deviasi standar dari tingkat pengembalian (return) suatu produk (Hull, 2009).

Volatilitas menyatakan parameter untuk harga saham yang berubah-ubah setiap waktu. Menurut Beckers (1980), berdasarkan pengamatannya di pasar harga opsi saham dipengaruhi oleh volatilitas yang tidak konstan, sehingga terdapat hubungan kebalikan antara nilai harga saham dengan nilai volatilitas saham. Untuk varian pengembalian saham yang membuat harga saham berubah-ubah dinamakan volatilitas. Model volatilitas stokastik ialah salah satu pendekatan untuk mengatasi perubahan harga di pasar yang tidak 
konstan. Apabila mengasumsikan bahwa volatilitas harga di pasar adalah konstan maka nilainya menjadi tidak akurat. Terdapat berbagai model dalam perhitungan volatilitas stokastik salah satunya model constant elasticity of variance yang sesuai dengan permasalahan untuk mendeskripsikan hubungan kebalikan antara volatilitas dengan harga saham yang tidak konstan maka dapat menggunakan model constant elasticity of variance (CEV) (Randal, 1998). CEV merupakan pengembangan model BlackScholes untuk harga saham dengan volatilitas stokastik (Beckers, 1980).

Pada perhitungan harga opsi menggunakan model CEV akan menghasilkan nilai yang lebih realistis karena mempertimbangkan volatilitas yang berubahubah sesuai kondisi nyata di pasar. Penulis tertarik untuk menentukan nilai opsi saham beli tipe Eropa pada PT. Telekomunikasi Indonesia menggunakan model constant elasticity of variance, dengan harapan menghasilkan nilai yang sesuai dengan keadaan pasar serta sebagai acuan para investor dalam mengelola saham yang dimiliki.

Pada umumnya nilai volatilitas selalu berubah-ubah sampai tanggal jatuh tempo. Dalam perhitungan menggunakan model BlackScholes mengasumsikan nilai volatilitas ialah konstan atau diestimasi dari implied volatility metode lain yang digunakan adalah stokastik volatilitas. Asumsi ini membuat perhitungan nilai opsi saham model Black-Scholes kurang tepat. Untuk menanggulangi masalah ini maka model CEV yang diperkenalkan oleh John Cox (1975) merupakan pengembangan dari model Black-Scholes. Nilai volatilitas model BlackScholes dapat dihitung menggunakan rumus dibawah ini:

$$
\sigma_{B S}=\sqrt{249 \times \frac{\sum_{t-1}^{n}\left(R_{t}-\overline{R_{t}}\right)^{2}}{n-1}}
$$

dengan 249 merupakan jumlah hari perdagangan per tahun, $\overline{R_{t}}$ merupaka rata-rata return harga saham pada periode $t$. dan $R_{t}$ merupakan return saham seperti yang dinyatakan sebagai

$$
R_{t}=\ln \left(\frac{S_{t}}{S_{t-1}}\right)
$$

$S_{t}$ merupakan harga saham saat periode $t$ dan $S_{t-1}$ merupakan harga saham pada periode sebelum periode $t$. Harga opsi beli tipe Eropa yang ditentukan oleh rumus Black Scholes adalah:

$$
\begin{gathered}
C=S_{0} N\left(d_{1}\right)-K e^{-r T} N\left(d_{2}\right) \\
d_{1}=\frac{\ln \left(\frac{S_{0}}{K}\right)+\left(r+\frac{\sigma_{B S}{ }^{2}}{2}\right) T}{\sigma_{B S} \sqrt{T}} \\
d_{2}=d_{1}-\sigma_{B S} \sqrt{T}
\end{gathered}
$$$$
\text { dengan }
$$

dan untuk menentukan nilai $\mathcal{N}\left(d_{1,2}\right)$ dapat menggunakan persamaan dibawah ini:

$$
\mathcal{N}\left(d_{1,2}\right)=\int_{-\infty}^{x} \frac{1}{\sqrt{2 \pi}} e^{\frac{1}{2} y^{2}} d y
$$

Pada model CEV terdapat hubungan antara harga saham dan volatilitas yang dinyatakan sebagai (Schroder, 1989):

$$
\sigma(S, t)=\sigma_{B S} \cdot S_{0}{ }^{1-\beta}
$$

parameter rentang untuk $\beta$ dalam model CEV $0<\beta<1$. Berdasarkan persamaan di atas, jika nilai $\beta=1$ maka nilai volatilitasnya sama dengan model Black-Scholes. Jika nilai $\beta<$ 1 akan terjadi hubungan kebalikan antara harga saham dan volatilitas, atau sering disebut dengan hubungan invers. Pada pembahasan model CEV digunakan nilai $\beta<1$, berdasarkan nilai volatilitas yang diperoleh maka dapat ditentukan nilai opsi beli Eropa dengan memperhitungkan tingkat bebas risiko yaitu:

$$
\begin{aligned}
C=S\left(1-X^{2}\left(2 z \cdot \frac{3-2 \beta}{1-\beta}\right)\right) \\
\quad-K e^{r T} X^{2}\left(2 x \cdot \frac{1}{1-\beta} \cdot 2 z\right)
\end{aligned}
$$

dengan

$$
\begin{aligned}
& k=\frac{2 r}{2 \sigma^{2}(1-\beta)(\exp (2(2-\beta) r T)-1)} \\
& x=k S^{2(1-\beta)} \exp (2(1-\beta) r T) \\
& z=k K^{2(1-\beta)}
\end{aligned}
$$

\section{METODE PENELITIAN}

Data yang digunakan dalam penelitian ini adalah data kuantitatif. Dalam penelitian ini data kuantitatif yang digunakan berupa data harian harga penutupan (close price) saham yang diperoleh dari PT. Telekomunikasi Indonesia selama tiga tahun, dimulai 4 Agustus 2014 sampai 31 Juli 2017 yang diakses melalui http://finance.yahoo.com/. Langkah-langkah dalam menentukan nilai opsi saham beli tipe Eropa menggunakan model constant elasticity of variance sebagai berikut: 
1. Mengumpulkan data saham selama tiga tahun, mulai dari tahun 2014 sampai dengan tahun 2017.

2. Menentukan nilai return dari data saham yang digunakan menggunakan persamaan (2)

3. Menghitung nilai volatilitas pada model Black-Scholes menggunakan Persamaan (1).

4. Melakukan perhitungan komponen $d_{1}$ dan $d_{2}$ menggunakan Persamaan (4) dan (5) dalam perhitungan opsi model BlackScholes.

5. Menentukan nilai $\mathcal{N}\left(d_{1}\right)$ dan $\mathcal{N}\left(d_{2}\right)$ pada model Black-Scholes menggunakan Persamaan (6).

6. Menghitung nilai opsi beli model BlackScholes menggunakan Persamaan (3).

7. Menghitung nilai volatilitas untuk model constant elasticity of variance (CEV) menggunakan Persamaan (7).

8. Menghitung nilai opsi beli model constant elasticity of variance (CEV) menggunakan Persamaan (8).

9. Interpretasi hasil.

\section{HASIL DAN PEMBAHASAN}

Data yang digunakan dalam penelitian ini berupa data harian harga penutupan (close price) saham yang diperoleh dari PT. Telekomunikasi Indonesia selama tiga tahun periode waktu 4 Agustus 2014 sampai dengan dari 31 Juli 2017 sebanyak 735 keluaran saham. Data tersebut digunakan untuk menentukan return saham PT. Telekomunikasi Indonesia. Langkah-langkah dalam menentukan harga opsi ialah:

\section{Menentukan nilai return saham menggunakan persamaan (2):}

$$
\begin{aligned}
R_{t} & =\ln \left(\frac{S_{t}}{S_{t-1}}\right) \\
R_{1} & =\ln \frac{2.710}{2.690}=0,007407
\end{aligned}
$$

Nilai rata-rata return dapat dihitung menggunakan Microsoft Excel.

Menetukan karakteristik data dapat dengan melihat nilai statistika deskriptif dari nilai tingkat pengembalian (return). Nilai statistika deskriptif ini diperoleh dengan menghitung nilai mean, varians, dan standar deviasi menggunakan Microsoft Excel sehingga diperoleh hasil pada Tabel 1 berikut:
Tabel 1. Perhitungan Mean, Variansi, dan Deviasi Standar dalam Return Saham

\begin{tabular}{|c|c|}
\hline Karakteristik & Nilai \\
\hline Mean & 0,000758 \\
\hline Varian & 0,0002356 \\
\hline Deviasi Standar & 0,015352 \\
\hline
\end{tabular}

Tabel 1 menunjukan bahwa rata-rata return saham PT. Telkom adalah 0,000758, dengan varians yang diperoleh sebesar 0,0002356, dan deviasi standar yang di dapat ialah 0,015352 .

Pada penentuan nilai kontrak opsi tipe Eropa terdapat variabel-variabel yang digunakan yakni

a. Harga saham awal $\left(S_{0}\right)$

Karena harga saham yang digunakan adalah harga penutupan saham harian PT. Telekomunikasi dari 4 Agustus 2014 sampai 31 Juli 2017 maka harga saham awal yang digunakan adalah harga penutupan saham yaitu sebesar 4.560

b. Waktu jatuh tempo (T)

Waktu jatuh tempo ditetapkan selama enam bulan atau 0,5 tahun.

c. Harga kesepakan atau strike price adalah harga yang diperoleh dari kesepakatan antara pihak penjual dan pembeli sebesar 4.700

d. Tingkat suku bunga bebas resiko Bank Indonesia sebesar 6\% atau 0,06.

\section{Penentuan nilai opsi saham beli tipe Eropa menggunakan model Black-Scholes}

Nilai volatilitas tahunan dapat dihitung menggunakan persamaan (1) sehingga diperoleh:

$$
\begin{aligned}
& \sigma=\sqrt{249 \times \frac{\sum_{t-1}^{n}\left(R_{t}-\overline{R_{t}}\right)^{2}}{n-1}} \\
& \sigma=\sqrt{249} \times 0,015352 \\
& \sigma=0,242255
\end{aligned}
$$

dengan 249 merupakan jumlah hari perdagangan per tahun. Jadi diperoleh nilai volatilitas tahunan saham PT. Telkom adalah 0,242255 atau $24 \%$.

Setelah mendapatkan nilai variabel volatilitas dalam menentukan harga opsi, selanjutnya akan dihitung nilai opsi beli tipe Eropa dengan menggunakan model BlackScholes yang terdapat pada persamaan (3). Untuk menghitung nilai $d_{1}$ dan $d_{2}$ dapat menggunakan persamaan (4) dan (5), yakni 


$$
\begin{aligned}
=\frac{\ln \left(\frac{S_{0}}{K}\right)+\left(r+\frac{\sigma^{2}}{2}\right) T}{\sigma \sqrt{T}} \\
=\frac{\ln \left(\frac{4.560}{4.700}\right)+\left(0,06+\frac{(0,242255)^{2}}{2}\right) 0.5}{0,242255 \sqrt{1}}
\end{aligned}
$$$$
=0,08424 \text {; }
$$

$$
\begin{aligned}
d_{2} & =\frac{\ln \left(\frac{S_{0}}{K}\right)+\left(r-\frac{\sigma_{B S}{ }^{2}}{2}\right) T}{\sigma_{B S} \sqrt{T}} \\
& =d_{1}-\sigma_{B S} \sqrt{T} \\
& =0,08424-0.242255 \sqrt{0.5} \\
& =-0,08705 .
\end{aligned}
$$

Maka dalam hal ini nilai $\mathcal{N}\left(d_{1}\right)$ dan $\mathcal{N}\left(d_{2}\right)$ yang diperoleh dengan menggunakan persamaan (6) adalah:

$$
\begin{aligned}
& \mathcal{N}\left(d_{1}\right)=0,53357 \\
& \mathcal{N}\left(d_{2}\right)=0,46531
\end{aligned}
$$

Sehingga dapat disimpulkan untuk hasil opsi beli ialah:

$$
\begin{aligned}
& C=S_{0} N\left(d_{1}\right)-K e^{-r T} N\left(d_{2}\right) \\
& =4.560(0,53357)-4.700 e^{-0.06(0.5)}(0,46531) \\
& =310,73
\end{aligned}
$$

\section{Penentuan nilai opsi saham beli tipe Eropa menggunakan model Constant Elasticity of Variance}

Model CEV merupakan model pengembangan dari model Black-Scholes. Jika model Black-Scholes menggunakan asumsi bahwa nilai volatilitas konstan, maka pada model CEV menggunakan nilai volatilitas yang tidak konstan mengikuti kondisi di pasar. Pada model CEV terdapat hubungan antara harga saham dengan volatilitas, untuk memperoleh nilai volatilitas maka menggunakan nilai volatilitas pada model Black-Scholes yang diperoleh dari data harian pada PT Telekomunikas Indonesia yakni $\left(\sigma_{B S}\right)=0.24$, untuk parameter rentang untuk $\beta$ dalam model CEV $0<\beta<1$ nilai parameter rentang $\beta$ yang digunakan dalam perhitungan nilai opsi beli model CEV adalah 0,3, 0,4, dan 0,5. Selanjutnya perhitungan volatilitas model CEV menggunakan persamaan (7) dengan nilai parameter $\beta$ yang digunakan ialah 0,3 yakni:

$$
\begin{gathered}
\sigma(S, t)=\sigma_{B S} \cdot S_{0}{ }^{1-\beta} \\
\sigma(S, t)=0,24 \cdot 4.560^{1-0,3}
\end{gathered}
$$

$$
\sigma(S, t)=83,39
$$

Selanjutnya untuk hasil perhitungan parameter $\beta$ untuk nilai 0,4 dan 0,5 dapat dilihat pada tabel 2. Berdasarkan nilai volatilitas yang diperoleh maka dapat ditentukan nilai opsi beli Eropa dengan memperhitungkan tingkat bebas risiko menggunakan persamaan (8) yakni:

$$
\begin{aligned}
C=S\left(1-X^{2}\left(2 z \cdot \frac{3-2 \beta}{1-\beta}\right)\right) \\
\quad-K e^{r T} X^{2}\left(2 x \cdot \frac{1}{1-\beta} \cdot 2 z\right)
\end{aligned}
$$

dengan

$$
\begin{gathered}
k=\frac{2 r}{2 \sigma^{2}(1-\beta)(\exp (2(2-\beta) r T)-1)} \\
x=k S^{2(1-\beta)} \exp (2(1-\beta) r T) \\
z=k K^{2(1-\beta)}
\end{gathered}
$$

untuk menggunakan parameter nilai $\beta$ ialah 0,3 dengan hasil nilai volatilitas CEV 83,39 maka diperoleh nilai opsi beli CEV sebesar 474,87 selanjutnya nilai $\beta(0,4$ dan 0,5$)$ dapat dilihat pada tabel 2.

Tabel 2. Nilai rekomendasi investor terhadap model CEV

\begin{tabular}{|c|c|c|c|}
\hline $\begin{array}{l}\text { Nilai Opsi } \\
\text { saham beli } \\
\text { Model BS }\end{array}$ & Nilai $\beta$ & $\begin{array}{l}\text { Nilai } \\
\text { Volatilitas }\end{array}$ & $\begin{array}{l}\text { Nilai Opsi } \\
\text { Beli } \\
\text { Model } \\
\text { CEV }\end{array}$ \\
\hline 310,73 & 0,3 & 87,39 & 474,87 \\
\hline 310,73 & 0,4 & 37,63 & 498,10 \\
\hline 310,73 & 0,5 & 16,20 & 528,80 \\
\hline
\end{tabular}

Hasil dari tabel diperoleh nilai perhitungan opsi CEV untuk parameter rentang untuk $\beta$ dalam model CEV adalah $0<\beta<1$ yakni nilai $\beta(0.3 ; 0.4 ; 0.5)$ dengan hasil nilai opsi saham beli CEV $(474,87 ; 498,10 ; 528,80)$, semakin kecil nilai $\beta$ maka semakin besar pengaruh nilai harga saham pada opsi. Berdasarkan hasil nilai dari tabel 1 maka diperoleh nilai opsi beli saham Eropa yang disimpulkan apabila hasil nilai opsi saham yang dihitung lebih besar dari harga opsi saham yang dihitung menggunakan model Black-Scholes maka investor disarankan untuk beli. Investor disarankan membeli opsi saham hanya jika tidak diketahui tidak ada dividen yang dibayarkan karena jika terdapat pembayaran dividen maka nilai opsi saham melalui perhitungan lebih rendah dari harga saham yang ditawarkan. 


\section{KESIMPULAN DAN SARAN}

\section{Simpulan}

Berdasarkan hasil dan pembahasan yang telah diuraikan, estimasi nilai opsi saham beli menggunakan model constant elasticity of variance $(\mathrm{CEV})$ pada data historis harga saham penutupan PT Telekomunikasi Indonesia periode 2014 sampai 2017 dicatat mulai 4 Agustus 2014 sampai 31 Juli 2017 dengan langkah awal yaitu menghitung tingkat pengembalian (return), Kemudian menghitung nilai volatilitas Black-Scholes yang akan digunakan untuk memperoleh nilai volatilitas dan nilai opsi saham beli pada Model constant elasticity of variance, selanjutnya melakukan perbandingan dengan hasil nilai opsi saham beli mengggunakan Model Black-Scholes. Apabila hasil nilai opsi saham yang dihitung menggunakan model CEV lebih besar dari harga opsi saham yang dihitung menggunakan model Black-Scholes maka investor disarankan untuk beli. Dalam perhitungan model CEV terdapat pengaruh nilai $\beta$ yang sangat besar untuk melihat pengaruh harga saham terhadap opsi. Investor disarankan beli dalam arti dikarenakan harga saham yang ditawarkan lebih murah dari harga sebenarnya alhasil investor akan memperoleh keuntungan.

Dari hasil uraian dan perhitungan harga opsi beli berdasarkan contoh kasus penerapan model CEV memiliki hasil nilai volatillitas yang berubah-ubah sehingga terdapat hubungan kebalikan antara nilai volatilitas dengan harga opsi saham di pasar.

\section{Saran}

Hasil yang diperoleh dari model CEV masih banyak dinyatakan dalam berbagai versi, antara lain menurut John Cox, Mark Schoder, Stan Becker. Menurut John Cox memperkenalkan nilai opsi saham menggunakan fungsi Bessel. Mark Schoder mengenalkan nilai opsi saham yang didekati dengan distribusi chi square noncentral. Sedangkan Stan Becker mengenalkan penilaian harga opsi saham Model CEV yang dikembangkan pada kasus yang lebih khusus yaitu model absolut (ketika nilai parameter volatilitasnya sama dengan nol). Penulisan tugas akhir ini hanya sebatas pada pendekatan harga opsi saham pada tipe Eropa. Untuk penulisan selanjutnya dapat dikembangkan pada tipe Amerika atau versi lain yang telah disebutkan sebelumnya.

\section{DAFTAR PUSTAKA}

Beckers, S. (1980). The Constant Elasticity of Variance and Its Implications for Option Pricing. Journal of Finance Vol 35, No 3, 661-673.

Black, F. \& Scholes, M. (1973). The Pricing of Options and Corporate Liabilities. The Journal of Political Economy, 637-654.

Cox, J. (1975). Notes on Option Pricing I, In Constant Elasticity of Variance Diffusions. California: Working paper Stanford University.

Hull, J. (2009). Option, Futures, and other Derivatives (7 ed.). New Jersey: PrenticeHall.

Randal, J. (1998). The Constant Elasticity of Variance Option Pricing Model . Thesis.

Schroder, M. (1989). The Constant Elasticity of Variance Option Pricing Formula. Jurnal of Finance, Vol 44, No 1, 211-219. 